\title{
Article
}

\section{Betel Nut Chewing Decreased Calcaneus Ultrasound T-Score in a Large Taiwanese Population Follow-Up Study}

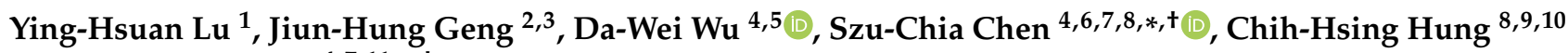 \\ and Chao-Hung Kuo $4,7,11, *,+$
}

1 Department of Post Baccalaureate Medicine, Kaohsiung Medical University, Kaohsiung 807, Taiwan; u107000007@gap.kmu.edu.tw

2 Department of Urology, Kaohsiung Municipal Siaogang Hospital, Kaohsiung Medical University, Kaohsiung 812, Taiwan; u9001090@gmail.com

3 Department of Urology, Kaohsiung Medical University Hospital, Kaohsiung Medical University, Kaohsiung 807, Taiwan

4 Department of Internal Medicine, Kaohsiung Municipal Siaogang Hospital, Kaohsiung Medical University, Kaohsiung 812, Taiwan; u8900030@yahoo.com.tw

5 Division of Pulmonary and Critical Care Medicine, Department of Internal Medicine, Kaohsiung Medical University Hospital, Kaohsiung Medical University, Kaohsiung 807, Taiwan

6 Division of Nephrology, Department of Internal Medicine, Kaohsiung Medical University Hospital, Kaohsiung Medical University, Kaohsiung 807, Taiwan

7 Faculty of Medicine, College of Medicine, Kaohsiung Medical University, Kaohsiung 807, Taiwan

8 Research Center for Environmental Medicine, Kaohsiung Medical University, Kaohsiung 807, Taiwan; pedhung@gmail.com

9 Department of Pediatrics, Kaohsiung Medical University Hospital, Kaohsiung Medical University, Kaohsiung 807, Taiwan

check for

updates

Citation: Lu, Y.-H.; Geng, J.-H.; Wu, D.-W.; Chen, S.-C.; Hung, C.-H.; Kuo, C.-H. Betel Nut Chewing Decreased Calcaneus Ultrasound T-Score in a Large Taiwanese Population Follow-Up Study. Nutrients 2021, 13, 3655. https://doi.org/10.3390/ nu13103655

Academic Editor: Cristiana Cipriani

Received: 18 September 2021

Accepted: 18 October 2021

Published: 19 October 2021

Publisher's Note: MDPI stays neutral with regard to jurisdictional claims in published maps and institutional affiliations.

Copyright: (c) 2021 by the authors. Licensee MDPI, Basel, Switzerland. This article is an open access article distributed under the terms and conditions of the Creative Commons Attribution (CC BY) license (https:/ / creativecommons.org/licenses/by/ $4.0 /)$.
10 Department of Pediatrics, Kaohsiung Municipal Siaogang Hospital, Kaohsiung Medical University, Kaohsiung 812, Taiwan

11 Division of Gastroenterology, Department of Internal Medicine, Kaohsiung Medical University Hospital, Kaohsiung Medical University, Kaohsiung 807, Taiwan

* Correspondence: scarchenone@yahoo.com.tw (S.-C.C.); kjh88kmu@gmail.com (C.-H.K.); Tel.: +886-7-8036783 (ext. 3440) (S.-C.C.); Fax: +886-7-8063346 (S.-C.C.)

+ Both are equal contributors.

Abstract: Chewing betel nut is common in Taiwan. Although previous studies have shown that chewing betel nuts is associated with adverse health effects, findings about the impact on bone density have been inconsistent. Therefore, the aim of this study was to investigate the correlation between betel nut chewing and calcaneus ultrasound T-score in a longitudinal study of 118,856 participants from the Taiwan Biobank. Of these participants, 27,002 were followed up with for a median of 4 years. The T-score of the calcaneus was measured in the non-dominant foot using ultrasound. Multivariable analysis showed that a history of chewing betel nut (coefficient $\beta=-0.232 ; p<0.001$ ) was significantly associated with low baseline T-score in all participants $(n=118,856)$. In addition, a long duration of betel nut chewing (per 1 year; coefficient $\beta=-0.003 ; p=0.022$ ) was significantly associated with a low baseline T-score in the participants with a history of chewing betel nut $(\mathrm{n}=7210)$. Further, a long duration of betel nut chewing (per 1 year; coefficient $\beta=-0.004 ; p=0.039$ ) was significantly associated with a low $\Delta T$-score in the participants with a history of chewing betel nut $(n=1778)$ after 4 years of follow-up. In conclusion, our results showed that betel nut chewing was associated with a decrease in calcaneus ultrasound T-score, and thus, it is important to stop chewing betel nut to help prevent an increased risk of osteoporosis in the Taiwanese population.

Keywords: calcaneus ultrasound; betel nut chewing; follow-up; Taiwan Biobank

\section{Introduction}

Osteoporosis is a serious skeletal disease that is associated with clinical consequences including fragility fractures typically involving the wrist, humerus, vertebrae, hip, and 
pelvis [1]. Fragility fractures can result in persistent pain, disability, economic burden, and increased morbidity [2]. The epidemiological features of osteoporosis are associated with advanced age and female sex [3]. Known risk factors contributing to bone density loss include alcohol abuse, smoking, insufficient physical activity, calcium or vitamin D deficiency, long-term use of glucocorticoids, and low body mass index (BMI) [4,5]. A better understanding of the potential risk factors of osteoporosis would help to prevent the disease. Therefore, it is important to investigate factors associated with an increase in the risk of developing osteoporosis.

According to the World Health Organization, 600 million people chew betel nut worldwide. Betel nut chewing has a long history related to economic and cultural factors in Taiwan [6], where the estimated prevalence is approximately $10 \%$, or about 970,000 adults [7]. However, betel nut chewing is associated with a wide range of diseases including pharyngeal and oral cancer, obesity, metabolic syndrome, neuronal injury, cardiac arrhythmias, myocardial ischemia, sub-mucosal fibrosis, hepatotoxicity, and asthma [8]. These adverse health effects are caused by betel nut-derived alkaloids, specifically arecoline [9]. Arecoline is a bioactive aldehyde that can be detoxified through various metabolic pathways [10]. Nitrosation of arecoline produces nitrosamines such as 3-(methylnitrosamino)propionitrile (MNPN), which has been shown to be a strong carcinogen, inducing tumors in in vivo and in vitro experiments [11,12]. Excess exposure to other betel nut components such as polyphenols and tannins also results in the generation of reactive oxygen species, leading to oxidative stress and inflammatory reactions in cardiovascular and other tissues [13]. Regarding the influence of betel nut chewing on bone, a clinical study of 114 participants revealed that betel quid chewing was associated with a decrease in radiographic alveolar bone density [14]. However, two in vivo studies showed that arecoline and phenolics could act as antioxidants and could ameliorate osteoporosis $[15,16]$. Therefore, findings on the association between betel nut chewing and osteoporosis are inconsistent, and further studies are needed to elucidate this issue.

Due to the limited data and the lack of a large cohort follow-up study on the association between betel nut chewing and calcaneus ultrasound T-score, the aim of this study was to explore the correlation between betel nut chewing and calcaneus ultrasound T-score in a longitudinal study of around 120,000 participants from the Taiwan Biobank (TWB). Follow-up data were analyzed to elucidate the link between betel nut chewing and changes in calcaneus ultrasound T-score.

\section{Materials and Methods}

\subsection{Ethics Statement}

This study followed the Declaration of Helsinki and was approved by the Institutional Review Board (IRB) of Kaohsiung Medical University Hospital (KMUHIRB-E(I)-20210058). Ethical approval for the TWB was granted by the IRB on Biomedical Science Research, Academia Sinica, Taiwan, and the Ethics and Governance Council of the TWB. All of the participants provided written informed consent.

\section{2. $T W B$}

The TWB was established to promote health care and chronic disease prevention in response to the aging population and longer average life expectancy in Taiwan. As such, the TWB includes lifestyle, genetic, and medical data on Taiwanese communitybased volunteers aged 30 to 70 years of age with no history of cancer $[17,18]$. After signing informed consent, all of the enrolled volunteers are asked to undergo a face-to-face interview and a physical examination and to provide a blood sample. Body height and weight and BMI $\left(\mathrm{kg} / \mathrm{m}^{2}\right)$ are recorded during the physical examination, and personal information, diet, and personal and family medical histories and lifestyle factors are recorded during the in-person interview via a questionnaire.

In this study, 121,423 participants were screened, of whom 2567 were excluded due to incomplete ultrasound data. The remaining 118,856 participants had complete calcaneus 
ultrasound measurements and were included in the baseline study. Of these participants, 27,002 received follow-up examinations after a median of 4 years. A further 165 participants without complete ultrasound measurements during the follow-up period were excluded, and the remaining 26,837 participants were included in the follow-up study (Figure 1).

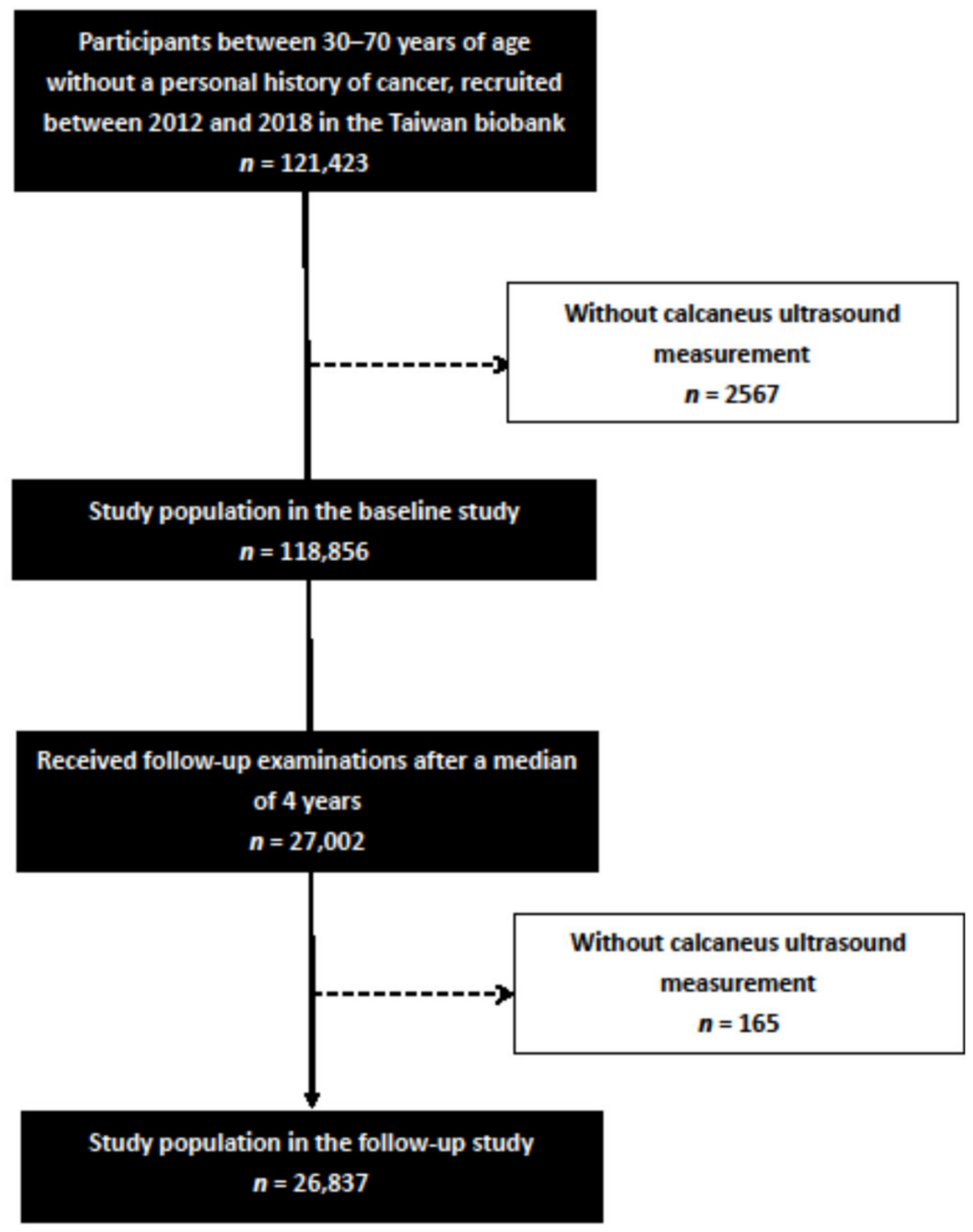

Figure 1. Flowchart of study population.

\subsection{Collection of Study Variables}

We also recorded baseline variables including age and sex, smoking history, diabetes mellitus $(\mathrm{DM})$ and hypertension. In addition, laboratory data including white blood cell (WBC) count, hemoglobin, fasting glucose, triglycerides, total cholesterol, highdensity lipoprotein [HDL]-cholesterol, low-density lipoprotein (LDL)-cholesterol, estimated glomerular filtration rate (eGFR), and uric acid were also recorded. The eGFR was calculated using the 4-variable modification of diet in renal disease study equation: eGFR $\left(\mathrm{mL} / \mathrm{min} / 1.73 \mathrm{~m}^{2}\right)=175 \times(\mathrm{Scr})-1.154 \times($ Age $)-0.203 \times(0.742$ if female $) \times(1.212$ if African American) [19]. 


\subsubsection{Assessment of Betel Nut Chewing}

The participants were asked the following question(s): "Have you ever chewed betel nut?" ("Yes" or "No") and "How many years have you chewed betel nut?" if they answered "Yes" to the first question.

\subsubsection{Assessment of Calcaneus Ultrasound T-Score}

An ultrasound device (Achilles InSight, GE, Madison Heights, USA) was used to measure the T-score $\left(\mathrm{g} / \mathrm{cm}^{2}\right)$ of the calcaneus in the non-dominant foot. The calcaneus ultrasound T-score was calculated as (T-score of the participant-mean T-score in young adults)/the standard deviation of a normal young-adult population. Change in the calcaneus ultrasound T-score ( $\Delta \mathrm{T}$-score) were calculated as: follow-up T-score-baseline T-score.

\subsubsection{Statistical Analysis}

Data are presented as percentages or as means \pm standard deviations. The chi-square test was used to analyze between-group differences in categorical variables, and the independent $t$ test was used for continuous variables. One-way analysis of variance was used for multiple comparisons among the study groups. Multivariable linear regression analysis was used to identify associations between chewing betel nut and baseline T-score and $\Delta \mathrm{T}$-score. A $p$ value of less than 0.05 was considered to indicate a statistically significant difference. All statistical analyses were conducted using SPSS version 26.0 for Windows (SPSS Inc. Chicago, IL, USA).

\section{Results}

The mean age of the 118,856 enrolled participants was $49.9 \pm 10.9$ years and included 42,658 males and 76,198 females. The participants were stratified into two groups according to the baseline calcaneus ultrasound $\mathrm{T}$ score $\geq-2.5(\mathrm{n}=110,227 ; 92.7 \%)$ or $<-2.5$ $(\mathrm{n}=8629 ; 7.3 \%)$.

\subsection{Comparison of Clinical Characteristics among the Participants According to BASELINE Calcaneus Ultrasound T Score $\geq-2.5$ or $<-2.5$}

A comparison of the clinical characteristics between the participants with a baseline calcaneus ultrasound T score $\geq-2.5$ or $<-2.5$ is shown in Table 1. Compared to the participants with a baseline T-score $\geq-2.5$, those with a baseline T-score $<-2.5$ were older, predominantly male, had longer smoking and betel nut chewing histories, higher prevalence rates of DM and hypertension, higher levels of hemoglobin, fasting glucose, triglycerides, total cholesterol, HDL-cholesterol and LDL-cholesterol, lower BMI, lower baseline T-score, lower WBC count, and higher eGFR.

Table 1. Comparison of clinical characteristics among participants according to baseline calcaneus ultrasound $\mathrm{T}$ score $\geq-2.5$ or $<-2.5$.

\begin{tabular}{|c|c|c|c|}
\hline Characteristics & $\begin{array}{c}\text { T-Score } \geq-2.5 \\
(n=110,227)\end{array}$ & $\begin{array}{c}\text { T-Score }<-2.5 \\
(\mathrm{n}=8629)\end{array}$ & $p$ \\
\hline Age (year) & $49.3 \pm 10.9$ & $57.2 \pm 9.1$ & $<0.001$ \\
\hline Male gender $(\%)$ & 35.5 & 41.2 & $<0.001$ \\
\hline Smoking history (\%) & 27.0 & 30.1 & $<0.001$ \\
\hline $\mathrm{DM}(\%)$ & 5.0 & 6.9 & $<0.001$ \\
\hline Hypertension (\%) & 11.9 & 17.0 & $<0.001$ \\
\hline Betel nut chewing history (\%) & 5.9 & 8.7 & $<0.001$ \\
\hline BMI $\left(\mathrm{kg} / \mathrm{m}^{2}\right)$ & $24.3 \pm 3.8$ & $23.6 \pm 3.7$ & $<0.001$ \\
\hline Baseline T-score & $-0.18 \pm 1.49$ & $-3.1 \pm 0.49$ & $<0.001$ \\
\hline Laboratory parameters & & & \\
\hline White blood cell $\left(\times 10^{3} / \mathrm{uL}\right)$ & $5.8 \pm 1.6$ & $5.7 \pm 1.6$ & $<0.001$ \\
\hline Hemoglobin $(\mathrm{g} / \mathrm{dL})$ & $13.7 \pm 1.6$ & $13.8 \pm 1.5$ & 0.005 \\
\hline Fasting glucose (mg/dL) & $95.7 \pm 20.4$ & $98.3 \pm 23.4$ & $<0.001$ \\
\hline
\end{tabular}


Table 1. Cont.

\begin{tabular}{cccc}
\hline Characteristics & $\begin{array}{c}\text { T-Score } \geq-\mathbf{2 . 5} \\
\text { (n = 110,227) }\end{array}$ & $\begin{array}{c}\text { T-Score }<-\mathbf{2 . 5} \\
\text { (n = 8629) }\end{array}$ & $\boldsymbol{p}$ \\
\hline Triglyceride $(\mathrm{mg} / \mathrm{dL})$ & $115.2 \pm 94.6$ & $119.6 \pm 86.7$ & $<0.001$ \\
Total cholesterol $(\mathrm{mg} / \mathrm{dL})$ & $195.4 \pm 35.7$ & $199.0 \pm 37.0$ & $<0.001$ \\
HDL-cholesterol $(\mathrm{mg} / \mathrm{dL})$ & $54.5 \pm 13.4$ & $55.1 \pm 14.2$ & 0.001 \\
LDL-cholesterol $(\mathrm{mg} / \mathrm{dL})$ & $120.9 \pm 31.7$ & $122.3 \pm 32.5$ & $<0.001$ \\
eGFR $\left(\mathrm{mL} / \mathrm{min} / 1.73 \mathrm{~m}^{2}\right)$ & $33.3 \pm 46.3$ & $38.8 \pm 48.7$ & $<0.001$ \\
Uric acid $(\mathrm{mg} / \mathrm{dL})$ & $5.4 \pm 1.4$ & $5.4 \pm 1.4$ & 0.114 \\
\hline
\end{tabular}

Abbreviations. DM, diabetes mellitus; BMI, body mass index; HDL, high-density lipoprotein; LDL, low-density lipoprotein; eGFR, estimated glomerular filtration rate.

Figure 2 shows the distributions of those with calcaneus ultrasound T-score $\geq-1.0$, T-score -1.0 to -2.5 and T-score $<-2.5$ stratified by betel nut chewing history. There was a significant increasing trend $(p<0.001)$ in the T-score $<-2.5$ in the participants with a history of chewing betel nut. The prevalence rates of a T-score $\geq-1.0$, T-score -1.0 to -2.5 , and T-score $<-2.5$ in the participants with and without a history of chewing betel nut were $52.7 \%, 36.9 \%$, and $10.4 \%$ vs. $63.3 \%, 29.6 \%$ and $7.1 \%$, respectively $(p<0.001)$.

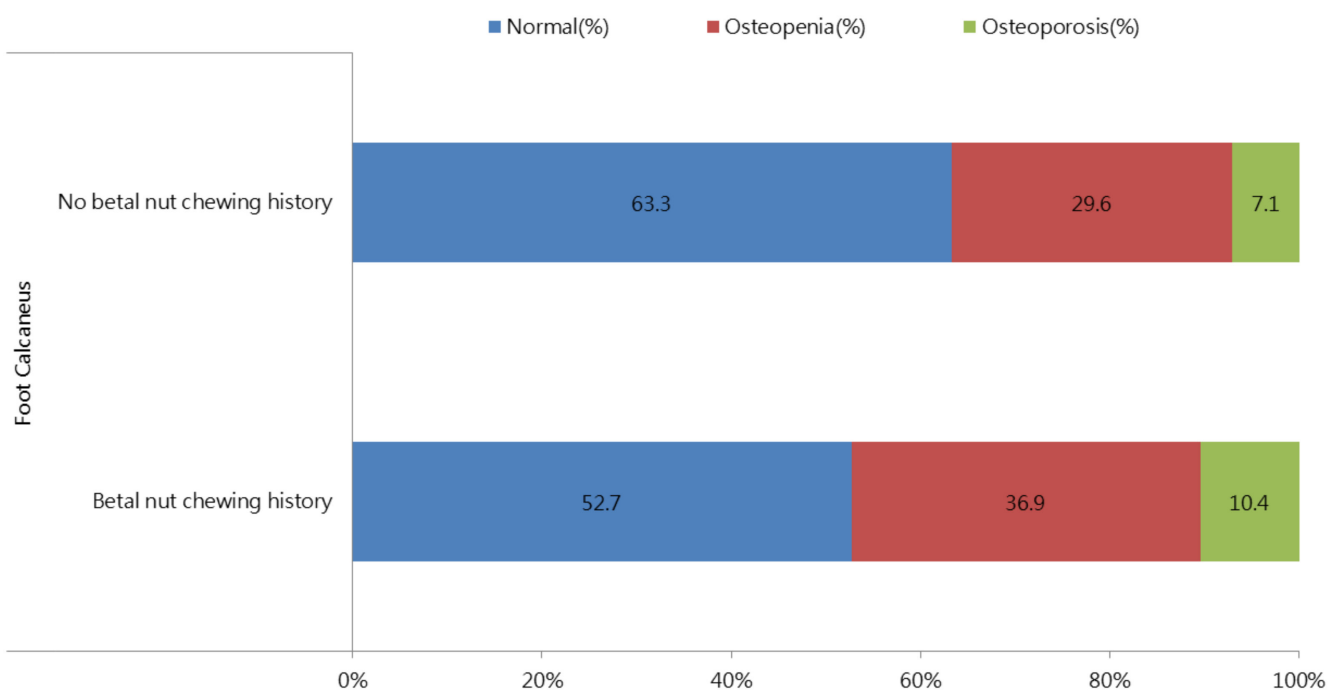

Figure 2. The distribution of calcaneus ultrasound T-score $\geq-1.0$, T-score -1.0 to -2.5 and T-score $<-2.5$, stratified by the betel nut chewing history. There was a significant trend for an increase $(p<0.001)$ in T-score $<-2.5$ in participants with betel nut chewing.

\subsection{Correlation between a History of Betel Nut Chewing and Baseline T-Score in All Participants}

Table 2 shows the determinants of the baseline calcaneus ultrasound T-score in all of the participants $(n=118,856)$ using multivariable linear regression analysis. After multivariable analysis (adjusted for betel nut chewing history, age, sex, smoking history, DM, hypertension, BMI, WBC, hemoglobin, fasting glucose, triglycerides, total cholesterol, HDL-cholesterol, LDL-cholesterol, eGFR, and uric acid), betel nut chewing history (unstandardized coefficient $\beta=-0.232 ; 95 \%$ confidence interval $(\mathrm{CI})=-0.271$ to $-0.193 ; p<0.001$ ), old age $(p<0.001)$, female sex $(p<0.001)$, no DM history $(p<0.001)$, hypertension history $(p<0.001)$, low BMI $(p<0.001)$, high WBC $(p<0.001)$, low hemoglobin $(p<0.001)$, high fasting glucose $(p=0.037)$, high triglycerides $(p<0.001)$, low HDL-cholesterol $(p<0.001)$, high LDL-cholesterol $(p=0.021)$, high eGFR $(p<0.001)$, and high uric acid $(p<0.001)$ were significantly associated with a low baseline T-score. We further performed a false discovery rate (FDR) test, and betel nut chewing history still had significant results $(p=0.013)$. 
Table 2. Association of betel nut chewing history with baseline calcaneus ultrasound T-score in all study participants $(n=118,856)$ using multivariable linear regression analysis.

\begin{tabular}{|c|c|c|}
\hline \multirow[b]{2}{*}{ Variables } & \multicolumn{2}{|c|}{ Multivariable (Baseline T-Score) } \\
\hline & $\begin{array}{c}\text { Unstandardized Coefficient } \\
\beta(95 \% \mathrm{CI})\end{array}$ & $p$ \\
\hline Betel nut chewing history & $-0.232(-0.271,-0.193)$ & $<0.001$ \\
\hline Age (per 1 year) & $-0.056(-0.057,-0.055)$ & $<0.001$ \\
\hline Male (vs. female) & $0.473(0.397,0.550)$ & $<0.001$ \\
\hline Smoking history & $-0.001(-0.024,0.022)$ & 0.955 \\
\hline DM & $0.096(0.052,0.140)$ & $<0.001$ \\
\hline Hypertension & $-0.070(-0.098,-0.042)$ & $<0.001$ \\
\hline BMI $\left(\right.$ per $\left.1 \mathrm{~kg} / \mathrm{m}^{2}\right)$ & $0.055(0.052,0.057)$ & $<0.001$ \\
\hline \multicolumn{3}{|l|}{ Laboratory parameters } \\
\hline White blood cell (per $\left.1 \times 10^{3} / \mathrm{uL}\right)$ & $-0.093(-0.018,-0.007)$ & $<0.001$ \\
\hline Hemoglobin (per $1 \mathrm{~g} / \mathrm{dL})$ & $0.018(0.011,0.025)$ & $<0.001$ \\
\hline Fasting glucose (per $1 \mathrm{mg} / \mathrm{dL}$ ) & $-0.001(-0.001,0)$ & 0.037 \\
\hline Triglyceride (per $1 \mathrm{mg} / \mathrm{dL}$ ) & $-0.001(-0.001,0)$ & $<0.001$ \\
\hline Total cholesterol (per $1 \mathrm{mg} / \mathrm{dL}$ ) & $1.022 \times 10^{-5}(-0.001,0.001)$ & 0.984 \\
\hline HDL-cholesterol (per $1 \mathrm{mg} / \mathrm{dL}$ ) & $0.002(0.001,0.004)$ & $<0.001$ \\
\hline LDL-cholesterol (per 1 mg/dL) & $-0.001(-0.002,0)$ & 0.021 \\
\hline eGFR (per $1 \mathrm{~mL} / \mathrm{min} / 1.73 \mathrm{~m}^{2}$ ) & $-0.010(-0.011,-0.009)$ & $<0.001$ \\
\hline Uric acid (per 1 mg/dL) & $-0.014(-0.022,-0.006)$ & $<0.001$ \\
\hline
\end{tabular}

Values expressed as unstandardized coefficient $\beta$ and $95 \%$ confidence interval (CI). Abbreviations are the same as in Table 1.

We further performed subgroup analysis after excluding age older than 50 years in women to survey the association between a history of betel nut chewing and the baseline $\mathrm{Z}$-score $(\mathrm{n}=77,676)$. After multivariable adjustment, betel nut chewing history (unstandardized coefficient $\beta=-0.201 ; 95 \% \mathrm{CI}=-0.241$ to $-0.161 ; p<0.001$ ) was significantly associated with a low baseline Z-score.

3.3. Correlation between Duration of Chewing Betel Nut and Baseline T-Score in the Participants with a History of Betel Nut Chewing

Table 3 shows the determinants of the baseline T-score in the participants with a history of chewing betel nut $(\mathrm{n}=7210)$ using multivariable linear regression analysis. After multivariable analysis (adjusted for duration of betel nut chewing, age, sex, smoking history, DM, hypertension, BMI, WBC, hemoglobin, fasting glucose, triglycerides, total cholesterol, HDL-cholesterol, LDL-cholesterol, eGFR, and uric acid), a long duration of chewing betel nut (per 1 year; unstandardized coefficient $\beta=-0.003 ; 95 \% \mathrm{CI}=-0.006$ to $-0.001 ; p=0.022)$, old age $(p<0.001)$, male sex $(p=0.010)$, smoking history $(p=0.010)$, low BMI $(p<0.001)$, high WBC $(p=0.022)$, low hemoglobin $(p<0.001)$, and high eGFR $(p<0.001)$ were significantly associated with a low baseline T-score in the participants with a history of chewing betel nut. We further performed an FDR test, and the duration of chewing betel nut still had significant results $(p=0.044)$.

We further performed subgroup analysis after excluding age older than 50 years of in women to survey the association between the duration of chewing betel nut and the baseline Z-score $(\mathrm{n}=7106)$. After multivariable adjustment, a long duration of betel nut chewing (per 1 year; unstandardized coefficient $\beta=-0.003 ; 95 \% \mathrm{CI}=-0.006$ to $0 ; p=0.074$ ) was not but was borderline significantly associated with a low baseline Z-score. 
Table 3. Association of betel nut chewing years with baseline calcaneus ultrasound T-score in study participants with betel nut chewing history $(n=7210)$ using multivariable linear regression analysis.

\begin{tabular}{|c|c|c|}
\hline \multirow[b]{2}{*}{ Variables } & \multicolumn{2}{|c|}{ Multivariable (T-Score) } \\
\hline & $\begin{array}{c}\text { Unstandardized Coefficient } \beta \\
(95 \% \text { CI })\end{array}$ & $p$ \\
\hline Betel nut chewing years (per 1 year) & $-0.003(-0.006,-0.001)$ & 0.022 \\
\hline Age (per 1 year) & $-0.026(-0.030,-0.023)$ & $<0.001$ \\
\hline Male (vs. female) & $-0.335(-0.589,-0.081)$ & 0.010 \\
\hline Smoking history & $-0.179(-0.315,-0.042)$ & 0.010 \\
\hline DM & $0.080(-0.048,0.208)$ & 0.219 \\
\hline Hypertension & $-0.061(-0.144,0.023)$ & 0.157 \\
\hline BMI (per $1 \mathrm{~kg} / \mathrm{m}^{2}$ ) & $0.036(0.027,0.045)$ & $<0.001$ \\
\hline Laboratory parameters & & \\
\hline White blood cell (per $\left.1 \times 10^{3} / \mathrm{uL}\right)$ & $-0.036(-0.054,-0.019)$ & 0.022 \\
\hline Hemoglobin (per $1 \mathrm{~g} / \mathrm{dL})$ & $0.061(0.035,0.087)$ & $<0.001$ \\
\hline Fasting glucose (per $1 \mathrm{mg} / \mathrm{dL})$ & $0(-0.001,0.002)$ & 0.622 \\
\hline Triglyceride (per $1 \mathrm{mg} / \mathrm{dL}$ ) & $0(-0.001,0)$ & 0.125 \\
\hline Total cholesterol (per $1 \mathrm{mg} / \mathrm{dL}$ ) & $0.001(-0.002,0.004)$ & 0.567 \\
\hline HDL-cholesterol (per $1 \mathrm{mg} / \mathrm{dL})$ & $0.001(-0.004,0.005)$ & 0.795 \\
\hline LDL-cholesterol (per $1 \mathrm{mg} / \mathrm{dL}$ ) & $-0.001(-0.004,0.002)$ & 0.403 \\
\hline eGFR (per $1 \mathrm{~mL} / \mathrm{min} / 1.73 \mathrm{~m}^{2}$ ) & $-0.004(-0.005,-0.002)$ & $<0.001$ \\
\hline Uric acid (per $1 \mathrm{mg} / \mathrm{dL}$ ) & $-0.015(-0.038,0.009)$ & 0.224 \\
\hline
\end{tabular}

Values expressed as unstandardized coefficient $\beta$ and $95 \%$ confidence interval (CI). Abbreviations are the same as in Table 1.

3.4. Correlation between Duration of Chewing Betel Nut and $\Delta T$-Score in the Participants with a History of Chewing Betel Nut

Table 4 shows the determinants of the $\Delta \mathrm{T}$-score in the participants with a history of chewing betel nut $(\mathrm{n}=1778)$ using multivariable linear regression analysis. After multivariable analysis (adjusted for duration of betel nut chewing, age, sex, smoking history, DM, hypertension, BMI, WBC, hemoglobin, fasting glucose, triglycerides, total cholesterol, HDL-cholesterol, LDL-cholesterol, eGFR, and uric acid), a long duration of betel nut chewing (per 1 year; unstandardized coefficient $\beta=-0.004 ; 95 \% \mathrm{CI}=-0.008$ to 0 ; $p=0.039$ ) was significantly associated with a low $\Delta \mathrm{T}$-score. We further performed an FDR test, and duration of chewing betel nut still had significant results $(p=0.040)$.

Table 4. Association of betel nut chewing years with calcaneus ultrasound $\Delta \mathrm{T}$-score in study participants with betel nut chewing history $(n=1778)$ using multivariable linear regression analysis.

\begin{tabular}{|c|c|c|}
\hline \multirow[b]{2}{*}{ Variables } & \multicolumn{2}{|c|}{ Multivariable ( $\Delta$ T-Score) } \\
\hline & $\begin{array}{c}\text { Unstandardized Coefficient } \\
\beta(95 \% \text { CI })\end{array}$ & $p$ \\
\hline Betel nut chewing years (per 1 year) & $-0.004(-0.008,0)$ & 0.039 \\
\hline Age (per 1 year) & $0.001(-0.004,0.006)$ & 0.754 \\
\hline Male (vs. female) & $0.051(-0.254,0.355)$ & 0.745 \\
\hline Smoking history & $0.032(-0.169,0.233)$ & 0.757 \\
\hline $\mathrm{DM}$ & $-0.092(-0.278,0.095)$ & 0.334 \\
\hline Hypertension & $0.075(-0.044,0.194)$ & 0.218 \\
\hline BMI (per 1 kg/m²) & $-0.006(-0.020,0.008)$ & 0.428 \\
\hline Laboratory parameters & & \\
\hline White blood cell (per $1 \times 10^{3} / \mathrm{uL}$ ) & $-0.005(-0.032,0.021)$ & 0.688 \\
\hline Hemoglobin (per $1 \mathrm{~g} / \mathrm{dL}$ ) & $-0.009(-0.047,0.029)$ & 0.638 \\
\hline Fasting glucose (per $1 \mathrm{mg} / \mathrm{dL}$ ) & $0(-0.002,0.002)$ & 0.832 \\
\hline Triglyceride (per $1 \mathrm{mg} / \mathrm{dL}$ ) & $-5.358 \times 10^{-5}(-0.001,0.001)$ & 0.890 \\
\hline Total cholesterol (per 1 mg/dL) & $-0.001(-0.005,0.004)$ & 0.829 \\
\hline HDL-cholesterol (per $1 \mathrm{mg} / \mathrm{dL}$ ) & $0.003(-0.004,0.009)$ & 0.430 \\
\hline LDL-cholesterol (per $1 \mathrm{mg} / \mathrm{dL})$ & $6.104 \times 10^{-5}(-0.005,0.005)$ & 0.980 \\
\hline eGFR (per $1 \mathrm{~mL} / \mathrm{min} / 1.73 \mathrm{~m}^{2}$ ) & $0(-0.003,0.002)$ & 0.715 \\
\hline Uric acid (per $1 \mathrm{mg} / \mathrm{dL}$ ) & $0.029(-0.006,0.063)$ & 0.105 \\
\hline
\end{tabular}

Values expressed as unstandardized coefficient $\beta$ and $95 \%$ confidence interval (CI). Abbreviations are the same as in Table 1. 
We further performed subgroup analysis after excluding age older than 50 years in women to survey the association between duration of chewing betel nut and $\Delta Z$-score $(\mathrm{n}=1749)$. After multivariable adjustment, a long duration of betel nut chewing (per 1 year; unstandardized coefficient $\beta=-0.004 ; 95 \% \mathrm{CI}=-0.008$ to $0 ; p=0.040$ ) was significantly associated with a low $\Delta \mathrm{Z}$-score.

\section{Discussion}

In this study, we investigated the associations between chewing betel nut and the calcaneus ultrasound T-score at baseline and follow-up. A total of 118,856 participants were analyzed at baseline, and 27,002 were analyzed after a median follow-up period of 4 years. Overall, we found that a history of chewing betel nut and a long duration of chewing betel nut were associated with a low baseline T-score. Furthermore, after 4 years of follow-up, a long duration of chewing betel nut was associated with a greater decrease in the T-score.

The first important finding of this study is that betel nut chewing was associated with a low baseline T-score, and that a long duration of chewing betel nut was associated with a greater decrease in T-score after follow-up. These results indicate that betel nut chewing plays an important role in increasing the risk of osteoporosis and that the detrimental effect on bone density increases with the duration of use. With regard to the underlying mechanism, preliminary research has reported that betel nut extracts themselves do not alter the expression of osteoprotegerin (OPG), but rather inhibit the expression of alkaline phosphatase (ALP) and stimulate the production of receptor activator of nuclear factor-kB ligand (RANKL) in human osteoblasts [20]. Of these factors, ALP is involved in skeletal mineralization and osteoblastic differentiation, while RANKL binds RANK, which then affects osteoclastic bone resorption [21,22]. In addition, OPG, a soluble decoy receptor, has been shown to stop bone resorption and osteoclast activation by binding with RANKL [23]. However, contrasting results were also reported in an in vivo study, in which betel nut extracts prevented bone density loss by inducing an increase in OPG and inhibiting RANKL expression [15]. The anti-osteoporosis effects have been attributed to arecoline, which has been shown to inhibit the downstream transcription factors nuclear factor kappa B (NF- $\mathrm{kB}$ ) and mitogen-activated protein kinases activated by RANKL-RANK interactions [16,24]. However, a relatively low concertation of betel nut extract was used in these anti-osteoporosis experiments, whereas a higher baseline concentration of arecoline is found in the saliva of habitual chewers $[16,25,26]$. Moreover, betel nut is often chewed with a mixture of various ingredients such as tobacco, betel leaf, and calcium hydroxide, traditionally called slaked lime [27]. A previous cross-sectional study reported that Southeast-Asian women with a history of chewing betel nut were associated with an increased bone mineral density (BMD), which may be due to the mixture containing calcium in addition to betel nut [28]. In summary, betel nut has both potential pharmacological applications and toxic effects depending on the exposure dose, duration, and other additives. Therefore, the daily consumption of the hazardous components in betel nut will lead to a cumulative dose that may contribute to osteoporosis by disrupting the balance of molecules such as ALP and RANKL in bone remodeling.

The second important finding of this study is that a high WBC was associated with a low T-score. Increasing evidence has demonstrated that immune responses modify bone remodeling through complex interactions involving neutrophils, lymphocytes, and various cytokines in different diseases and physical conditions such as aging [29]. For example, estrogen deficiency has been shown to induce an expansion of B lymphocytes and T lymphocytes, leading to an increased production of RANKL [30-32]. Besides RANKL, an elevation in T lymphocyte-derived tumor necrosis factor-alpha (TNF- $\alpha$ ) and the interleukin (IL)-1 family, which act as central mediators in osteoporosis by increasing osteoclast precursors and suppressing osteoblast activity [33,34], has been reported in postmenopausal women and patients with rheumatic diseases [32,35,36]. However, Valderrábano et al. (2017) reported that bone loss was associated with increased neutrophil count, decreased monocyte count, and decreased lymphocyte count in elderly men [37]. In addition, an 
increased neutrophil lymphocyte ratio has been associated with lower BMD in elderly people with osteoporosis. Aging-related chronic inflammation can also cause an increase in neutrophils and the activation of osteoclasts by RANKL and a wide range of inflammatory cytokines [38]. Taken together, WBCs play a critical role in bone remodeling based on the overlap of pathways between immune activation and bone turnover. Since we only evaluated total WBC count in this study, further studies are needed to investigate the relationship between WBC subtypes and BMD. In addition, our results showed that a high WBC was associated with a low T-score in participants with a history of chewing betel nut. Faouzi et al. (2018) demonstrated that the aqueous fraction of betel nut extracts could stimulate cytokine production, particularly IL-8, in various immune cell lines and human primary immune cells [39]. Since IL-8 induces chemotaxis primarily in neutrophils [40], it is possible that an increased neutrophil lymphocyte ratio may be associated with low T-score in betel nut chewers.

The third important finding of this study is that high levels of fasting glucose, triglycerides, and LDL-cholesterol and a low level of HDL-cholesterol were associated with a low T-score. These findings are consistent with the study by Yamaguchi et al., who reported that both low HDL-cholesterol and high LDL-cholesterol were correlated with low BMD [41]. Bijelic et al. reported that high triglycerides and high LDL-cholesterol but not HDL-cholesterol were associated with bone loss [42]. In addition, Holmberg et al. reported that impaired fasting glucose, an intermediate state between normoglycemia and diabetes, resulted in a small but significant increase in the risk of osteoporotic fractures [43]. Furthermore, hyperglycemia, high triglycerides, low HDL-cholesterol, hypertension, and central obesity are features of metabolic syndrome, which has been associated with osteoporosis via various mechanisms [44]. For example, high glucose levels can lead to the generation of advanced glycation end-products through the nonenzymatic glycation of macromolecules (proteins, lipids, and nucleic acids) and can then induce osteocyte sclerostin expression, which is a negative regulator of osteoblast differentiation [45]. In addition, advanced glycation end-products have been shown to stimulate the expression of peroxisome proliferator-activated receptor gamma (PPAR $\gamma$ ) [46], leading to an increase in adipogenesis and a reduction in osteoblastogenesis since adipocytes and osteoblasts share the same progenitors [47]. Increased levels of circulating lipids such as LDL-cholesterol can increase the risk of their oxidation, which then accumulate in the subendothelial matrix of the vasculature and bone. Consequently, oxidized LDL-cholesterol promotes bone resorption by inducing the endothelial expressions of monocyte chemotactic factors and macrophage colony stimulating factor (M-CSF), which then leads to the differentiation of precursor cells into osteoclasts [48]. In contrast, HDL-cholesterol inhibits the oxidation of LDL-cholesterol and facilitates cholesterol transport from vessels back to the liver [49]; therefore, low HDL-cholesterol is associated with low BMD. However, high triglycerides may not be identified as an independent risk factor for osteoporosis since it is often associated with a higher BMI, which is a known protective factor for the skeleton [41]. In summary, alterations in lipid and glucose metabolism are strongly associated with bone remodeling.

Another interesting finding of this study is that a high level of uric acid was associated with a low T-score. Preliminary studies have demonstrated that elevated levels of serum uric acid and gout, a disease characterized by hyperuricemia and inflammation, are associated with an increased risk of hip fractures $[50,51]$. However, several studies have reported an association between a higher uric acid level and lower bone loss rate [52]. The effect of uric acid on bone is unclear since it has the ability to scavenge reactive oxygen species while also generating free radicals during the process of purine metabolism and uric acid degradation inside the cell [53]. The prooxidant effect of uric acid can promote the oxidation of LDL-cholesterol at a physiological concentration of around $0.5 \mathrm{nM}$ in human plasma [54]. Furthermore, excess uric acid can lead to the generation of proinflammatory cytokines such as IL-1 [55] and TNF- $\alpha$ [56] leading to bone resorption. In conclusion, the 
role of uric acid in osteoporosis depends on the balance between antioxidant activity and oxidative stress.

To the best of our knowledge, this is the first longitudinal study to examine the association between betel nut chewing and the duration of chewing with the calcaneus ultrasound T-score. The main novelty and strengths of this study are the large-scale investigation and follow-up data. However, there are also several limitations. First, data on the use of medications were not available in the TWB, and certain medications may affect the development or prevention of increased risk of osteoporosis. Second, some information about inflammation, oxidative stress, bone resorption, and formation markers were lacking. Further studies are needed to assess the association between chewing betel nut with inflammation, oxidative stress, bone resorption, and formation markers. Third, the presence of T-score was identified using an ultrasound device rather than dual energy $\mathrm{X}$-ray absorptiometry (DXA). Although DXA is the most commonly used method to measure $\mathrm{BMD}$, quantitative ultrasound does not require the use of radiation, and it is relatively low cost and portable. In addition, a previous study in Chinese women showed that the Achilles InSight system could identify an increased risk of osteoporosis, which had been confirmed by axial BMD using DXA [57]. Finally, all of the participants in the TWB are of Chinese ethnicity, and as such, our findings may not be generalizable to other populations.

In conclusion, in this large follow-up study, we found that betel nut chewing was associated with an increased risk of osteoporosis, and that a long duration of betel nut chewing accelerated the decline in T-score. Our findings suggest that encouraging people to stop chewing betel nut should be taken into consideration for the prevention of an increased risk of osteoporosis in the Taiwanese population.

Author Contributions: Conceptualization, Y.-H.L., J.-H.G., D.-W.W., S.-C.C., C.-H.H. and C.-H.K.; methodology, S.-C.C., J.-H.G. and D.-W.W.; software, S.-C.C. and J.-H.G.; validation, S.-C.C. and C.-H.K.; formal analysis, S.-C.C. and J.-H.G.; investigation, Y.-H.L., J.-H.G., D.-W.W., S.-C.C., C.-H.H. and C.-H.K.; writing-original draft preparation, Y.-H.L. and S.-C.C.; writing-review and editing, S.-C.C. and C.-H.K.; supervision, S.-C.C.; C.-H.H. and C.-H.K.; project administration, S.-C.C.; funding acquisition, S.-C.C. All authors have read and agreed to the published version of the manuscript.

Funding: This work was supported partially by the Research Center for Environmental Medicine, Kaohsiung Medical University, Kaohsiung, Taiwan from The Featured Areas Research Center Program within the framework of the Higher Education Sprout Project by the Ministry of Education (MOE) in Taiwan and by Kaohsiung Medical University Research Center Grant (KMU-TC109A01-1).

Institutional Review Board Statement: The study was conducted according to the guidelines of the Declaration of Helsinki, and ap-proved by the Institutional Review Board of Kaohsiung Medical University Chung-Ho Memorial Hospital (KMUHIRB-E(I)-20180242 and 2018/8/3 approval.

Informed Consent Statement: Informed consent was obtained from all subjects involved in the study.

Data Availability Statement: The data underlying this study is from the Taiwan Biobank. Due to restrictions placed on the data by the Personal Information Protection Act of Taiwan, the minimal data set cannot be made publicly available. Data may be available upon request to interested researchers. Please send data requests to: Szu-Chia Chen, Division of Nephrology, Department of Internal Medicine, Kaohsiung Medical University Hospital, Kaohsiung Medical University.

Conflicts of Interest: The authors declare no conflict of interest.

\section{References}

1. Riggs, B.L.; Melton, L.J., 3rd. The worldwide problem of osteoporosis: Insights afforded by epidemiology. Bone 1995, 17 (Suppl. S5), 505s-511s. [CrossRef]

2. Harvey, N.; Dennison, E.; Cooper, C. Osteoporosis: Impact on health and economics. Nat. Rev. Rheumatol. 2010, 6, 99-105. [CrossRef] [PubMed]

3. Holroyd, C.; Cooper, C.; Dennison, E. Epidemiology of osteoporosis. Best Pract. Res. Clin. Endocrinol. Metab. 2008, 22, 671-685. [CrossRef]

4. Golob, A.L.; Laya, M.B. Osteoporosis: Screening, prevention, and management. Med. Clin. N. Am. 2015, 99, 587-606. [CrossRef] [PubMed] 
5. Pisani, P.; Renna, M.D.; Conversano, F.; Casciaro, E.; Di Paola, M.; Quarta, E.; Muratore, M.; Casciaro, S. Major osteoporotic fragility fractures: Risk factor updates and societal impact. World J. Orthop. 2016, 7, 171-181. [CrossRef]

6. Tham, J.; Sem, G.; Sit, E.; Tai, M.C.-T. The ethics of betel nut consumption in Taiwan. J. Med. Ethics 2017, 43, 739-740. [CrossRef]

7. Ministry of Health and Welfare. 2020 Health Promotion Administration Annual Report. 2020. Available online: https://www. hpa.gov.tw/EngPages /Detail.aspx?nodeid=1070\&pid=13282 (accessed on 15 July 2021).

8. Garg, A.; Chaturvedi, P.; Gupta, P.C. A review of the systemic adverse effects of areca nut or betel nut. Indian J. Med. Paediatr. Oncol. 2014, 35, 3-9. [CrossRef]

9. Liu, Y.-J.; Peng, W.; Hu, M.-B.; Xu, M.; Wu, C.-J. The pharmacology, toxicology and potential applications of arecoline: A review. Pharm. Biol. 2016, 54, 2753-2760. [CrossRef]

10. Giri, S.; Idle, J.R.; Chen, C.; Zabriskie, T.M.; Krausz, K.W.; Gonzalez, F.J. A metabolomic approach to the metabolism of the areca nut alkaloids arecoline and arecaidine in the mouse. Chem. Res. Toxicol. 2006, 19, 818-827. [CrossRef]

11. Wenke, G.; Rivenson, A.; Brunnemann, K.D.; Hoffmann, D.; Bhide, S.V. A study of betel quid carcinogenesis. II. Formation of N-nitrosamines during betel quid chewing. IARC Sci. Publ. 1984, 57, 859-866.

12. World Health Organization. Betel-Quid and Areca-Nut Chewing and Some Areca-Nut Derived Nitrosamines; IARC: Lyon, France, 2005.

13. Nair, U.J.; Floyd, R.A.; Nair, J.; Bussachini, V.; Friesen, M.; Bartsch, H. Formation of reactive oxygen species and of 8hydroxydeoxyguanosine in DNA in vitro with betel quid ingredients. Chem.-Biol. Interact. 1987, 63, 157-169. [CrossRef]

14. Hsiao, C.-N.; Ting, C.-C.; Shieh, T.-Y.; Ko, E.C. Relationship between betel quid chewing and radiographic alveolar bone loss among Taiwanese aboriginals: A retrospective study. BMC Oral Health 2014, 14, 133. [CrossRef] [PubMed]

15. Li, S.; Chen, R.; Luo, K.; Guo, Y.; Xiao, M.; Du, G. Areca nut extract protects against ovariectomy-induced osteoporosis in mice. Exp. Ther. Med. 2017, 13, 2893-2899. [CrossRef]

16. Liu, F.-L.; Chen, C.-L.; Lai, C.-C.; Lee, C.-C.; Chang, D.-M. Arecoline suppresses RANKL-induced osteoclast differentiation in vitro and attenuates LPS-induced bone loss in vivo. Phytomedicine 2020, 69, 153195. [CrossRef]

17. Chen, C.-H.; Yang, J.-H.; Chiang, C.; Hsiung, C.-N.; Wu, P.-E.; Chang, L.-C.; Chu, H.-W.; Chang, J.; Yuan-Tsong, C.; Yang, S.-L.; et al. Population structure of Han Chinese in the modern Taiwanese population based on 10,000 participants in the Taiwan Biobank project. Hum. Mol. Genet. 2016, 25, 5321-5331. [CrossRef]

18. Fan, C.-T.; Hung, T.-H.; Yeh, C.-K. Taiwan Regulation of Biobanks. J. Law Med. Ethic 2015, 43, 816-826. [CrossRef]

19. Levey, A.S.; Bosch, J.P.; Lewis, J.B.; Greene, T.; Rogers, N.; Roth, D.R.; The Modification of Diet in Renal Disease Study Group. A more accurate method to estimate glomerular filtration rate from serum creatinine: A new prediction equation. Ann. Intern. Med. 1999, 130, 461-470. [CrossRef] [PubMed]

20. Ling, L.-J.; Ho, F.-C.; Chen, Y.-T.; Holborow, D.W.; Liu, T.-Y.; Hung, S.-L. Areca nut extracts modulated expression of alkaline phosphatase and receptor activator of nuclear factor kappaB ligand in osteoblasts. J. Clin. Periodontol. 2005, 32, 353-359. [CrossRef]

21. Yasuda, H.; Shima, N.; Nakagawa, N.; Yamaguchi, K.; Kinosaki, M.; Mochizuki, S.-I.; Tomoyasu, A.; Yano, K.; Goto, M.; Murakami, A.; et al. Osteoclast differentiation factor is a ligand for osteoprotegerin/osteoclastogenesis-inhibitory factor and is identical to TRANCE/RANKL. Proc. Natl. Acad. Sci. USA 1998, 95, 3597-3602. [CrossRef]

22. Stein, G.S.; Lian, J.B.; Owen, T.A. Relationship of cell growth to the regulation of tissue-specific gene expression during osteoblast differentiation. FASEB J. 1990, 4, 3111-3123. [CrossRef] [PubMed]

23. Hofbauer, L.C.; Lacey, D.; Dunstan, C.; Spelsberg, T.; Riggs, B.; Khosla, S. Interleukin-1 $\beta$ and tumor necrosis factor- $\alpha$, but not interleukin-6, stimulate osteoprotegerin ligand gene expression in human osteoblastic cells. Bone 1999, 25, 255-259. [CrossRef]

24. Walsh, M.C.; Choi, Y. Biology of the RANKL-RANK-OPG System in Immunity, Bone, and Beyond. Front. Immunol. $2014,5,511$. [CrossRef] [PubMed]

25. Cox, S.; Vickers, E.R.; Ghu, S.; Zoellner, H. Salivary arecoline levels during areca nut chewing in human volunteers. J. Oral Pathol. Med. 2010, 39, 465-469. [CrossRef] [PubMed]

26. Nair, J.; Ohshima, H.; Friesen, M.; Croisy, A.; Bhide, S.; Bartsch, H. Tobacco-specific and betel nut-specific N-nitroso compounds: Occurrence in saliva and urine of betel quid chewers and formation in vitro by nitrosation of betel quid. Carcinogenesis 1985, 6 , 295-303. [CrossRef] [PubMed]

27. Gupta, P.C.; Ray, C.S. Epidemiology of betel quid usage. Ann. Acad. Med. Singap. 2004, 33, 31-36. [PubMed]

28. Lauderdale, D.S.; Salant, T.; Han, K.L.; Tran, P.L. Life-course predictors of ultrasonic heel measurement in a cross-sectional study of immigrant women from Southeast Asia. Am. J. Epidemiol. 2001, 153, 581-586. [CrossRef] [PubMed]

29. Clowes, J.A.; Riggs, B.L.; Khosla, S. The role of the immune system in the pathophysiology of osteoporosis. Immunol. Rev. 2005, 208, 207-227. [CrossRef] [PubMed]

30. Masuzawa, T.; Miyaura, C.; Onoe, Y.; Kusano, K.; Ohta, H.; Nozawa, S.; Suda, T. Estrogen deficiency stimulates B lymphopoiesis in mouse bone marrow. J. Clin. Investig. 1994, 94, 1090-1097. [CrossRef]

31. Eghbali-Fatourechi, G.; Khosla, S.; Sanyal, A.; Boyle, W.J.; Lacey, D.L.; Riggs, B.L. Role of RANK ligand in mediating increased bone resorption in early postmenopausal women. J. Clin. Investig. 2003, 111, 1221-1230. [CrossRef]

32. D'Amelio, P.; Grimaldi, A.; Di, B.S.; Brianza, S.Z.; Cristofaro, M.A.; Tamone, C.; Giribaldi, G.; Ulliers, D.; Pescarmona, G.P.; Isaia, G. Estrogen deficiency increases osteoclasto-genesis up-regulating T cells activity: A key mechanism in osteoporosis. Bone 2008, 43, 92. [CrossRef] 
33. Kobayashi, K.; Takahashi, N.; Jimi, E.; Udagawa, N.; Takami, M.; Kotake, S.; Nakagawa, N.; Kinosaki, M.; Yamaguchi, K.; Shima, N.; et al. Tumor Necrosis Factor $\alpha$ Stimulates Osteoclast Differentiation by a Mechanism Independent of the Odf/Rankl-Rank Interaction. J. Exp. Med. 2000, 191, 275-286. [CrossRef]

34. Pfeilschifter, J.; Chenu, C.; Bird, A.; Mundy, G.R.; Roodman, D.G. Interleukin-1 and tumor necrosis factor stimulate the formation of human osteoclastlike cells in vitro. J. Bone Miner. Res. 1989, 4, 113-118. [CrossRef]

35. Fontova, R.; Gutiérrez, C.; Vendrell, J.; Broch, M.; Simón, I.; Fernández-Real, J.M.; Richart, C. Bone mineral mass is associated with interleukin 1 receptor autoantigen and TNF- $\alpha$ gene polymorphisms in post-menopausal Mediterranean women. J. Endocrinol. Investig. 2002, 25, 684-690. [CrossRef] [PubMed]

36. Ruscitti, P.; Cipriani, P.; Carubbi, F.; Liakouli, V.; Zazzeroni, F.; Di Benedetto, P.; Berardicurti, O.; Alesse, E.; Giacomelli, R. The Role of IL-1 $\beta$ in the Bone Loss during Rheumatic Diseases. Mediat. Inflamm. 2015, 12, 782382.

37. Valderrábano, R.J.; Lui, L.-Y.; Lee, J.; Cummings, S.R.; Orwoll, E.S.; Hoffman, A.R.; Wu, J.Y. Osteoporotic fractures in men (MrOS) study research group bone density loss is associated with blood cell counts. J. Bone Miner. Res. 2016, 32, 212-220. [CrossRef] [PubMed]

38. Chakravarti, A.; Raquil, M.A.; Tessier, P.; Poubelle, P.E. Surface RANKL of Toll-like receptor 4-stimulated human neutrophils activates osteoclastic bone resorption. Blood 2009, 8, 1633-1644. [CrossRef] [PubMed]

39. Faouzi, M.; Neupane, R.; Yang, J.; Williams, P.; Penner, R. Areca nut extracts mobilize calcium and release pro-inflammatory cyto-kines from various immune cells. Sci. Rep. 2018, 8, 1-13. [CrossRef]

40. Bickel, M. The role of interleukin-8 in inflammation and mechanisms of regulation. J. Periodontol. 1993, 64, 456-460.

41. Yamaguchi, T.; Sugimoto, T.; Yano, S.; Yamauchi, M.; Sowa, H.; Chen, Q.; Chihara, K. Plasma Lipids and Osteoporosis in Postmenopausal Women. Endocr. J. 2002, 49, 211-217. [CrossRef] [PubMed]

42. Bijelic, R.; Balaban, J.; Milicevic, S. Correlation of the Lipid Profile, BMI and Bone Mineral Density in Postmenopausal Women. Mater. Socio Med. 2016, 28, 412-415. [CrossRef]

43. Holmberg, A.H.; Nilsson, P.M.; Nilsson, J.A.; Akesson, K. The Association between Hyperglycemia and Fracture Risk in Middle Age. A Prospective, Population-Based Study of 22,444 Men and 10,902 Women. J. Clin. Endocrinol. Metab. 2008, 93, 815-822. [CrossRef]

44. Wong, S.K.; Chin, K.-Y.; Suhaimi, F.H.; Ahmad, F.; Ima-Nirwana, S. The relationship between metabolic syndrome and Osteoporosis: A Review. Nutrients 2016, 8, 347. [CrossRef]

45. Tanaka, K.I.; Yamaguchi, T.; Kanazawa, I.; Sugimoto, T. Effects of high glucose and advanced glycation end products on the ex-pressions of sclerostin and RANKL as well as apoptosis in osteocyte-like MLO-Y4-A2 cells. Biochem. Biophys. Res. Commun. 2015, 461, 193-999. [CrossRef]

46. Chen, Y.J.; Sheu, M.-L.; Tsai, K.S.; Yang, R.S.; Liu, S.H. Advanced Glycation End Products Induce Peroxisome ProliferatorActivated Receptor $\gamma$ Down-Regulation-Related Inflammatory Signals in Human Chondrocytes via Toll-Like Receptor-4 and Receptor for Advanced Glycation End Products. PLoS ONE 2013, 8, e66611. [CrossRef]

47. Akune, T.; Ohba, S.; Kamekura, S.; Yamaguchi, M.; Chung, U.I.; Kubota, N.; Terauchi, Y.; Harada, Y.; Azuma, Y.; Nakamura, K.; et al. PPARgamma insufficiency enhances osteogenesis through osteoblast formation from bone marrow progenitors. J. Clin. Investig. 2004, 113, 846-855. [CrossRef]

48. Tintut, Y.; Morony, S.; Demer, L.L. Hyperlipidemia promotes osteoclastic potential of bone marrow cells ex vivo. Arter. Thromb. Vasc. Biol. 2004, 24, e6-e10. [CrossRef]

49. Brites, F.; Martin, M.; Guillas, I.; Kontush, A. Antioxidative activity of high-density lipoprotein (HDL): Mechanistic insights into potential clinical benefit. BBA Clin. 2017, 8, 66-77. [CrossRef] [PubMed]

50. Paik, J.M.; Kim, S.C.; Feskanich, D.; Choi, H.K.; Solomon, D.H.; Curhan, G.C. Gout and risk of fracture in women: A Prospective cohort study. Arthritis Rheumatol. 2016, 69, 422-428. [CrossRef] [PubMed]

51. Mehta, T.; Bůžková, P.; Sarnak, M.J.; Chonchol, M.; Cauley, J.A.; Wallace, E.; Fink, H.A.; Robbins, J.; Jalal, D. Serum urate levels and the risk of hip fractures: Data from the cardiovascular health study. Metabolism 2015, 64, 438-446. [CrossRef] [PubMed]

52. Makovey, J.; Macara, M.; Chen, J.S.; Hayward, C.S.; March, L.; Seibel, M.; Sambrook, P.N. Serum uric acid plays a protective role for bone loss in peri- and postmenopausal women: A longitudinal study. Bone 2013, 52, 400-406. [CrossRef] [PubMed]

53. Sautin, Y.Y.; Johnson, R.J. Uric Acid: The Oxidant-Antioxidant Paradox. Nucleosides Nucleotides Nucleic Acids 2008, 27, 608-619. [CrossRef] [PubMed]

54. Santos, C.X.; Anjos, E.I.; Augusto, O. Uric acid oxidation by peroxynitrite: Multiple reactions, free radical formation, and amplification of lipid oxidation. Arch. Biochem. Biophys. 1999, 372, 285-294. [CrossRef]

55. Yokose, K.; Sato, S.; Asano, T.; Yashiro, M.; Kobayashi, H.; Watanabe, H.; Suzuki, E.; Sato, C.; Kozuru, H.; Yatsuhashi, H.; et al. TNF- $\alpha$ potentiates uric acid-induced interleukin-1 $\beta$ (IL-1 $\beta$ ) secretion in human neutrophils. Mod. Rheumatol. 2018, $28,513-517$. [CrossRef]

56. di Giovine, F.S.; Malawista, S.E.; Thornton, E.; Duff, G.W. Urate crystals stimulate production of tumor necrosis factor alpha from human blood monocytes and synovial cells. Cytokine mRNA and protein kinetics, and cellular distribution. J. Clin. Investig. 1991, 87, 1375-1381. [CrossRef]

57. Jin, N.; Lin, S.; Zhang, Y.; Chen, F. Assess the discrimination of Achilles InSight calcaneus quantitative ultrasound device for os-teoporosis in Chinese women: Compared with dual energy X-ray absorptiometry measurements. Eur. J. Radiol. 2010, 76, 265-268. [CrossRef] 